\title{
Projeto Conceitual de Embalagem para Memórias de Resultado de Urnas Eletrônicas sob a Abordagem do Design Colaborativo
}

\author{
Conceptual Package Design for Electronic Voting Machine's Pen Drives Using a \\ Collaborative Design Approach
}

BARROS, Rubenio dos Santos; Mestrando em Design; Universidade Federal de Santa Catarina rubeniobarros@hotmail.com

DINIZ, Raimundo Lopes; Bolsista de Produtividade FAPEMA; Programa de Pós-Graduação em Design (UFMA)

rl.diniz@ufma.br

\section{Resumo}

O presente artigo descreve o processo de redesign da embalagem para Memórias de Resultado (MRs), sob a premissa do design colaborativo, até a etapa conceitual (abrangendo a problematização de fatores inerentes à funcionalidade e ao uso, culminando com propostas de solução). Utilizou-se o Guia para o Desenvolvimento de Embalagens (GODE), com adaptações de técnicas relacionadas ao design colaborativo, de modo a envolver os usuários em potencial e especialistas que atuam como projetistas de embalagens. Como resultado, apresenta-se uma nova proposta de acondicionamento mais adequada às necessidades dos usuários, considerando-se o transporte e acondicionamento de MRs.

Palavras Chave: embalagens; MRs; design colaborativo.

\begin{abstract}
This article describes the redesign process of the package for Result Records (MRs), under the collaborative design premise, up to the conceptual stage (covering the problematization of factors inherent to functionality and use, culminating in a solution proposal). The Guide for Package Development (GODE) was used, adapting techniques related to collaborative design in order to engage potential users, as well as specialists who act as packaging designers. As result, a new package proposal is presented which is adequate to the needs of the users, considering the transportation and packaging of MRs.
\end{abstract}

Keywords: packaging; MRs; collaborative design. 


\section{Introdução}

De acordo com a Associação Brasileira de Embalagem - ABRE (2012), as embalagens apresentam como funções básicas a contenção, proteção (evitar danos a própria embalagem e ao produto contido) e a viabilização do transporte de produtos. Com a evolução das atividades, foi incorporada ainda a função de comunicação. E durante a realização dessas funções, as embalagens são submetidas a vários riscos como choques, aceleração, temperatura, vibração, compressão, oxidação, perfuração, esmagamento, entre outros (ABRE, 2012; PEDELHES, 2005).

Mestriner (2007) complementa que a embalagem pode envolver outros aspectos de uso, como os racionais, emocionais e simbólicos. Desta maneira, elementos como a forma, a cor e outros componentes visuais também podem ser considerados importantes por, principalmente, oferecerem possibilidades de disposição de informações. E o design de embalagens pode pontuar desde uma simples alteração na especificação do produto, como o peso, ou até mesmo gerar uma mudança mais ampla, envolvendo novos componentes, materiais e tecnologias (BUCCl, 2010).

Romano (1996) acrescenta que o conhecimento multidisciplinar é requisito importante ao projeto da embalagem de um produto, principalmente nas áreas de mercadologia, design e engenharia, resultando em informações cruciais para o sucesso da embalagem e, automaticamente, para o produto que esta contém. E a multidisciplinaridade pode conduzir, naturalmente, a um processo colaborativo, que se apresenta como importante na relação entre designers e profissionais de outras áreas, sendo que a colaboração no Design pode ser entendida como $\mathrm{o}$ ato ou o efeito produtivo ou criativo exercido em um grupo solidário de pessoas comprometidas com o trabalho compartilhado (HEEMANN; LIMA; CORRÊA, 2008).

Essas premissas também são importantes para os projetos de embalagem voltados ao suporte do processo eleitoral, onde as embalagens possuem papel relevante no acondicionamento da urna eletrônica (UE) e de seus componentes. Dentre esses componentes, encontram-se as Memórias de Resultado (MRs), que auxiliam no funcionamento das urnas e, portanto, contribuem diretamente no processo eleitoral brasileiro (JUSTIÇA ELEITORAL, 2012).

O transporte e acondicionamento de MRs precisa ser seguro e apresentar configurações que estejam de acordo com as demandas das tarefas, além de estar alinhado às características e limitações dos fatores humanos envolvidos. $E$ dada as necessidades e critérios de desenvolvimento de embalagens, bem como a demanda de acondicionamento de Memórias de Resultado, a presente pesquisa apresenta os resultados do desenvolvimento projetual da embalagem para MRs de urnas eletrônicas de um Tribunal Regional Eleitoral (TRE), enfocando no design colaborativo como elemento chave para eficiência do projeto.

Este estudo é uma seção da pesquisa intitulada "Design da embalagem para Memórias de Resultado (MRs) de urnas eletrônicas" (Resolução CONSEPE-UFMA n 1500, de 18 de outubro de 2016), sendo que todas as informações aqui divulgadas do TRE possuem autorização prévia para publicação, de acordo com o documento ${ }^{\circ}$ 094205/2016 e conforme a lei 11.419/2006.

\section{Justificativa}

A realização dos procedimentos do processo eleitoral é um sistema complexo e que envolve um vasto conjunto de fatores que precisam atuar coordenadamente para a sua correta execução, sendo que o transporte das MRs e dos demais componentes das urnas eletrônicas demandam a adaptação do sistema para as mais diversas condições estruturais do país. 
No intuito de facilitar o transporte desses componentes e reforçar a garantia do bom andamento do processo eleitoral, destaca-se a necessidade do redesign das embalagens das MRs, pois elas possuem diversas funcionalidades que vão desde a checagem inicial das urnas até o armazenamento do resultado final das eleições. Assim, a preservação da integridade das MRs contribui para a execução das atividades programadas e, também, para evitar possíveis funcionamentos inadequados/ineficientes das UEs durante a votação (JUSTIÇA ELEITORAL, 2012).

Para tal, é necessário considerar a função prática (de uso), focando nos aspectos funcionais e de usabilidade exigidos para otimizar os processos de acondicionamento, manuseio e transporte de MRs. E para que esses aspectos de uso sejam devidamente compreendidos, de modo a gerar resultados que estejam alinhados com as reais necessidades do produto e de quem utiliza esses componentes em suas atividades, é interessante a incorporação do design colaborativo.

Seu uso tem como finalidade permitir a relação dos diversos atores envolvidos, principalmente os humanos, para que se encontre uma alternativa satisfatória e eficiente de redesign, pois como afirmam por Heemann, Lima e Corrêa (2008), a colaboração no design pode ser o primeiro passo para o real alcance da colaboração que culmine na criação de produtos melhores.

\section{A Urna Eletrônica Eleitoral e as MRs}

Segundo a definição do Tribunal Superior Eleitoral - TSE (2010), a Urna Eletrônica - UE é um microcomputador de uso específico para eleições e apresenta-se com recursos de segurança, como o embaralhamento interno de dados, que garante o sigilo do voto e a confiabilidade do processo de votação. Esse equipamento genuinamente brasileiro agrega, além de segurança, facilidade, agilidade e transparência ao processo eleitoral, eliminando o risco de fraude.

Todos os modelos de UE existentes são compostos por dois módulos principais: o terminal do eleitor e o microterminal. O terminal do eleitor é o modulo onde é feita a interação entre a urna e o eleitor, registrando o voto. Já o microterminal habilita os eleitores para votação e possibilita o acompanhamento do processo pelo mesário (TSE, 2010; JUSTIÇA ELEITORAL, 2012).

A urna eletrônica é composta ainda por outros periféricos, mecanismos internos e acessórios que garantem o seu funcionamento. E dentre esses periféricos, encontra-se a Memória de Resultado. De acordo com a Justiça Eleitoral (2012), as Memórias de Resultado (Figura 1) são dispositivos de armazenamento USB de uso exclusivo nas urnas que contém informações necessárias e complementares para o funcionamento do sistema, sendo sua principal função o armazenamento do resultado das votações para posterior transmissão e apuração.

Figura 1 - Modelos de MRs

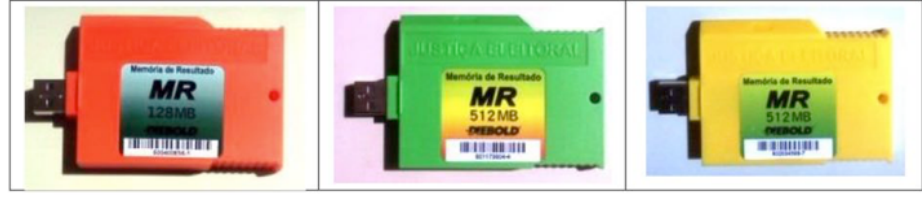

Fonte: Justiça Eleitoral (2012)

No processo de inicialização da urna, ela realiza a leitura da MR e carrega os aplicativos correspondentes previamente transferidos. Dentre as funções e aplicativos que são executados na 
urna a partir da MR, podem ser citados: treinamento do eleitor, treinamento do mesário, treinamento do sistema de apuração, votação (simulada ou oficial), justificativa eletrônica (simulada ou oficial), recuperador de dados, autoteste, dentre outros (JUSTIÇA ELEITORAL, 2012).

As MRs também apresentam papel significativo na resolução de alguns problemas que possam surgir durante a votação (data e hora incorretas, falha de periféricos, etc.). $E$, de acordo com o Manual de Exercitação de Urnas (JUSTIÇA ELEITORAL, 2012), em algumas situações em que há defeito na comunicação entre a MR e a urna, é necessária a substituição da própria urna, o que ressalta sua importância. Até mesmo na substituição de urnas defeituosas as MRs são elementos chave, pois elas são as responsáveis por transmitir os dados que permitirão essa substituição.

\section{Design Colaborativo e o Projeto de Embalagens}

Negrão e Camargo (2008, p. 205) consideram o projeto de embalagem "um trabalho de equipe, e uma equipe que só obtêm êxito quando consegue se comunicar e se unir em torno de um objetivo em comum". Em outras palavras, é um trabalho coletivo, onde cada elemento atuante é capaz de contribuir com suas especialidades para que o resultado seja bem-sucedido.

Dentro de um projeto de embalagem, o designer ou equipe de design pode se beneficiar da aproximação e colaboração dos usuários nos mais diversos âmbitos, indo desde as fases iniciais, onde podem ser coletadas e filtradas informações de delineamento e compreensão da demanda, até as etapas finais, como a elaboração e escolha de propostas. É obtida a partir dessa abordagem uma visão mais precisa e condizente com a realidade, baseada em quem de fato utilizará o resultado desenvolvido. $\mathrm{E}$ isso pode ser alcançado pelo design colaborativo.

Heemann, Lima e Corrêa (2008) ressaltam que o processo colaborativo no desenvolvimento de produtos pode aumentar a relação dos designers com outros profissionais. Os autores descrevem, ainda, que pelo reconhecimento do design como um processo de trabalho, é possível caracterizá-lo como um envolvimento compartilhado para que possa ser realizado. Desta maneira, a atuação do designer de forma colaborativa pode ser considerada conveniente e salutar para a melhoria das relações com outros profissionais no referido processo, implementando a troca de informações e ações adequadas para o desenvolvimento de novos produtos.

Para Fontana (2012), a inserção da premissa "colaboração" no desenvolvimento projetual ou no processo de design pode apontar para múltiplos critérios, caracterizando as ações em um âmbito interdisciplinar. Assim, neste contexto, há a elevação da complexidade do processo, ampliando a network entre os atores envolvidos nas operações projetuais.

Para Coutinho et al. (2010) apud Fontana (2012), o design colaborativo deve considerar uma abordagem mais humana, resultante da natureza das interações dos atores envolvidos no processo de design (aplicação metodológica), mesmo que possa afetar as tomadas de decisões quanto ao desenvolvimento do projeto.

De acordo com Heemann, Lima e Corrêa (2008), a colaboração no processo de design apresenta-se ainda como tendo uma relevância científica. Para os autores, tal relevância é pautada na pressão que há sob os designers quanto ao atendimento à múltiplos requisitos projetuais em um curto espaço de tempo, demandando, assim, formas aprimoradas de trabalho para a concepção de novos produtos face às exigências da tecnologia. Esta ação ao conceber o "redesign" ou o "design original", tendo como referência critérios multifacetados, pode ser encarada como um desafio. Portanto, a colaboração deve ser uma alternativa importante no 
processo de design para superar esse desafio (HEEMANN; LIMA; CORRÊA, 2008).

Assim, é possível considerar que o processo colaborativo pode ser relevante na construção de elementos teóricos e práticos no desenvolvimento de embalagens.

\section{Métodos e Técnicas}

Para a realização desta pesquisa, foi aplicado o método GODE - Guia de Orientação para o Desenvolvimento de Embalagens (MERINO, 2002). O método GODE é recomendado especificamente para o projeto de embalagens, levando em consideração critérios e elementos que são intrínsecos a esse tipo de produto. Contudo, houve a necessidade de adaptações com o intuito de incorporar técnicas relacionadas ao design colaborativo, de modo a aperfeiçoar o método para as especificidades da demanda, ampliar o envolvimento dos usuários em potencial e inserir no processo especialistas que atuam como projetistas de embalagens.

Isso enfatiza o desenvolvimento dos resultados como algo que partiu da natureza das interações e da comunicação eficiente dos envolvidos no processo, o que é advindo do design colaborativo e de seu caráter mais humanizado (COUTINHO et al., 2010, apud FONTANA, 2012; KLEINSMANN, 2006). Essa adaptação contribuiu também para um direcionamento técnicocientífico do método, substituindo elementos com vieses ligado à venda, marketing e mercado para dar foco ao usuário. A seguir, são descritas as etapas, sub etapas e as ferramentas utilizadas.

\subsection{Etapa 0: Encomenda}

Entra em foco nessa fase todo o detalhamento inicial dos problemas presentes na embalagem e toda informação referencial possível acerca dos usuários e das questões de uso. Tal etapa foi realizada por meio de visitas preliminares de campo, observações sistemáticas e assistemáticas, além de entrevistas não-diretivas e focalizadas acerca do contexto funcional das MRs, tendo como base o que é apresentado por Moraes \& Mont'Alvão (2009).

A Encomenda teve início a partir da apresentação do panorama geral inicial e da problematização feita pelos próprios usuários, de acordo com o seu ponto de vista. A apresentação envolveu o delineamento dos principais problemas observados, as características desejadas e os requisitos que deveriam ser alcançados no projeto. A partir dessas informações, foi iniciada uma análise técnica e aprofundada do problema. Foram feitas visitas no local de armazenamento das MRs e suas respectivas embalagens, mais especificamente na Seção de Mídias e Suprimentos (SEMSU), e na Seção de Administração e Manutenção de Urnas Eletrônicas (SEMUE), que realiza operações de software nas UEs com o auxílio das MRs.

Foram realizadas ao longo de 1 mês 14 entrevistas com o quadro de funcionários do TRE, mais especificamente com aqueles funcionários que tinham contato direto com as MRs, sendo eles o Chefe da SEMSU, a chefe da SEMUE, o Coordenador de Logística (COLOG), 02 estagiários, uma técnica judiciária e um analista da SEMUE, além de 02 estagiários, uma técnica de manutenção e 1 funcionário de serviços gerais da SEMSU, totalizando 11 funcionários.

\subsection{Etapa 1: levantamento de dados}

Foi feito o Estudo de Campo, com uma investigação do produto a fim de conhecer os meios de produção, materiais empregados e embalagens de finalidade equivalente ou similar. Foram mapeados virtual e presencialmente 40 modelos de embalagens que se destinavam ao acondicionamento de mídias de armazenamento de dados, como é o caso da MR. Em seguida, 
suas configurações foram estudadas de acordo com a classificação dos tipos de embalagem apresentada pela ABRE (2012), as análises de produto propostas por Löbach (2001) e frente a embalagens existentes para MRs em outros tribunais. Esse tipo de análise pode antecipar imprevistos e situações de risco, colaborando positivamente para o desenvolvimento da estratégia de design (BAXTER, 1998; MESTRINER, 2002).

\subsection{Etapa 2: análise, interpretação e organização de dados}

Para o mapeamento das características da atual embalagem, foram considerados os quesitos apresentados nas análises estrutural, funcional, dos materiais, dos processos de fabricação, e da configuração que foram descritas por Löbach (2001). Os dados foram organizados e agrupados de acordo com a funcionalidade ou característica sob análise, formando uma lista de verificação desses elementos. A partir daí, foram geradas as recomendações do design e da ergonomia para o aperfeiçoamento da embalagem, evidenciando suas vantagens para os usuários e para o sistema, tendo como base a lista de requisitos proposta por Rodriguez (1986).

\subsection{Etapa 3: fase de criação}

Fase de desenvolvimento de alternativas projetuais com base no conceito que foi estabelecido para a embalagem. Nesta etapa, que conta com as subfases de criação, geração de ideias, desenvolvimento de parâmetros e escolha da proposta final, foram inseridas técnicas que estimulassem a criação, sendo elas o Brainstorming, Brainwritting e o Círculo de Oportunidades (BAXTER, 1998; PMELINK, 2002). O design colaborativo esteve presente em todas as etapas do estudo, mas a etapa que contou com maior incorporação das ferramentas voltadas para a abordagem colaborativa foi a fase de criação, visando gerar a maior quantidade de informações.

$\mathrm{O}$ processo criativo ocorreu em diversos momentos desta fase, sendo refeito à medida que eram necessárias mais alternativas para as configurações da embalagem. Como possuíam caráter livre, surgiram alternativas variadas quanto à abordagem de solução da demanda.

Buscou-se ainda uma abordagem colaborativa, para coleta de opiniões, avaliação e seleção de ideias entre a equipe de design e os usuários, tendo sido discutidas alterações, insights e proposições de melhorias junto com os usuários no próprio local de trabalho, mais especificamente na SEMUE e na SEMSU. Ao mesmo tempo, foi solicitado o auxílio de profissionais específicos que poderiam contribuir na consistência da proposta final, estando esses procedimentos alinhados ao pensamento colaborativo. As ferramentas adotadas nesse sentido foram as técnicas "Thinking Out Loud" e a "Avaliação Cooperativa", utilizadas entre usuários e especialistas (MORAES E SANTA ROSA, 2012).

Como parte das adaptações, para se ter uma visão mais ampla a respeito dos aspectos técnicos utilizou-se a Técnica Delphi. Sua aplicação consistiu na apresentação do desenvolvimento e da problemática da pesquisa para especialistas da área do design, de materiais e processos, representação técnica e da ergonomia, a fim de que esses profissionais contribuíssem para o andamento da pesquisa com a tecnicidade e o conhecimento específico de cada área em que atuam (MORAES; SANTA ROSA, 2012; BAXTER, 1998).

Em paralelo, foram continuados os processos de criação, discussão e pré-seleção das ideias que se mostraram promissoras, com suas representações gráficas bi e tridimensionais com maior detalhamento sendo desenvolvidas à medida que as propostas iam sendo refinadas e estruturadas junto aos usuários, buscando permitir uma melhor percepção das configurações e componentes 
envolvidos. Essas ações foram desenvolvidas para que os indivíduos inseridos no processo colaborativo (os especialistas durante a proposição das recomendações técnicas, os usuários em potencial com a indicação das preferências e necessidades de uso, e os designers durante a gestão dos atores e integração das soluções) tivessem acesso a uma visão detalhada das alternativas. Para tal, foram utilizados os softwares Adobe Illustrator ${ }^{\circledR}$ e Photoshop ${ }^{\circledR}$ versões Creative Suite 6 de 2012 e Creative Cloud 2015.0.0, Google Sketchup Pro ${ }^{\circledR}$ versão 16.0.19913, Autodesk AutoCAD ${ }^{\circledR}$ versão 2014, e o programa de rendering Luxion Keyshot versões 2015 e 2016.

\subsection{Etapa 4: fase executiva}

Segundo Merino, Carvalho e Merino (2007), nesta fase a equipe de design planeja a produção do design aprovado, onde uma vez que os elementos a serem reproduzidos estão finalizados, se descrevem as especificações técnicas necessárias para os processos e materiais finais. Os autores afirmam que essas especificações são chaves para o êxito final da embalagem.

Enfatiza-se que, no presente artigo, serão apresentados os resultados relativos ao desenvolvimento da pesquisa até a geração de propostas conceituais de redesign.

\section{Resultados e Discussões}

\subsection{Etapa 0: Encomenda do trabalho}

A demanda foi apresentada à equipe de design pela comitiva da Coordenadoria de Logística do Tribunal, composta pelo chefe da COLOG, a chefe da SEMUE e um servidor da SEMSU. Foram introduzidos os conceitos iniciais sobre as funcionalidades das MRs, a importância das embalagens para o transporte dessas mídias em todas as 89 Zonas Eleitorais (locais de votação do estado), e as características desejadas, como a resistência, durabilidade e praticidade durante uso, que foram fatores apontados como comprometidos na embalagem utilizada naquele momento. Além disso, foram explanados os requisitos do projeto que deveriam estar inseridos na proposta final, como a necessidade de representação técnica e o detalhamento do processo de produção.

A partir dessas informações iniciais, foi feito um levantamento técnico por meio de visitas, observações e entrevistas, no qual percebeu-se que a demanda de acondicionamento de MRs no Tribunal analisado corresponde a cerca de 42 mil MRs, que auxiliam no funcionamento de 20.202 urnas eletrônicas. Seu acondicionamento é feito dentro de gavetas plásticas que, por sua vez, ficam em armários dentro do Fórum do Tribunal (Figura 2).

Figura 2 - Gavetas e armários para acondicionamento
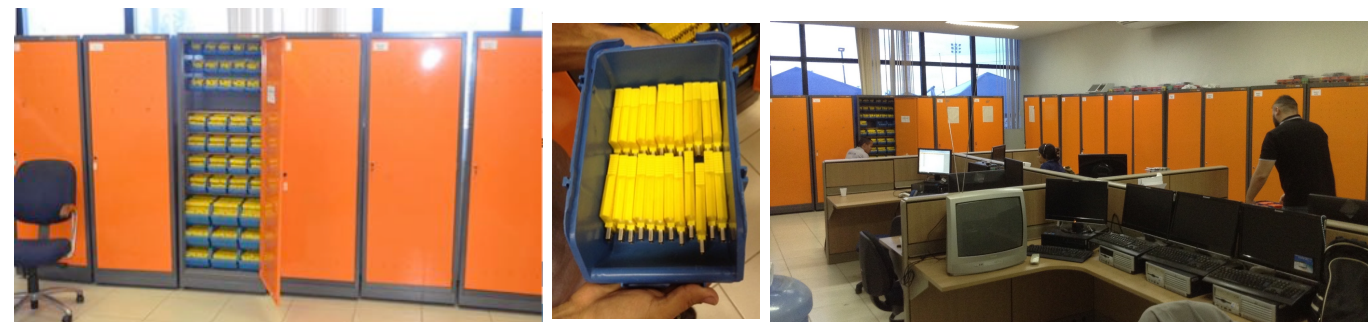

Fonte: autores

Quando há necessidade de movimentação das MRs, essa demanda pode ser suprida de formas diversas, sendo realizado desde o transporte de unidades manualmente, até o uso de 
caixas de papelão para o transporte de grandes quantidades. Mas o meio mais utilizado é com o auxílio das embalagens denominadas como maletas plásticas (Figura 3), que são importantes para o transporte das MRs para regiões no interior do estado ao qual o Tribunal analisado se destina.

Figura 3 - Maletas plásticas para transporte de MRs

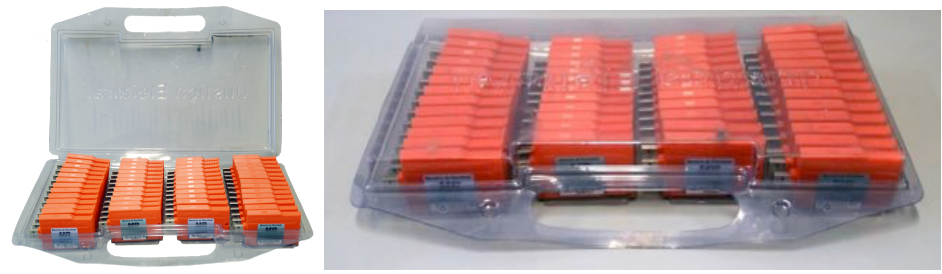

Fonte: autores

A embalagem das MRs se enquadra na classificação descrita pela ABRE (2012) como embalagem primária, que é aquela que está em contato direto com o produto e que atende aos aspectos pragmáticos do projeto (conter). Cada maleta pode acomodar $50 \mathrm{MRs}$, sendo que existe um total de 744 maletas plásticas, o que possibilita do transporte de 37.200 MRs.

\subsection{Etapa 1: Levantamento de dados}

Dentre as atividades envolvendo MRs, as que exigem a movimentação de um volume maior dessas mídias são o envio para as Zonas Eleitorais durante o período de eleição, e as manutenções preventiva e corretiva de UEs realizadas dentro do Fórum do TRE, no qual todas se utilizam em algum momento das maletas plásticas.

Acerca dos modelos de embalagem com finalidades similares levantados, em $67 \%$ dos casos (27), apenas embalagens primárias foram encontradas. Nos outros 13 modelos (33\%) havia a presença tanto de embalagens primárias quanto secundárias. A ABRE (2012) considera como embalagem primária aquela que tem contato direto com o produto embalado, e a secundária sendo aquela que contém uma ou mais embalagens primárias. Os formatos das embalagens encontradas variaram entre bandeja (60\%), estojo (27\%) e maleta (13\%), sendo que o modelo com maior capacidade era uma bandeja, comportando 120 mídias (cartões de memória). A grande maioria dos modelos (70\%) utilizava apenas um material em sua composição, sendo os mais utilizados o Poliestireno - PS e o Politereftalato de Etileno - PET, que são commodities.

Como um panorama geral construído a partir das análises propostas por Löbach (2001), pode-se afirmar que, sobre a possibilidade de empilhamento, apenas 4 (10\%) modelos não apresentavam essa função. Para a abertura e fechamento das embalagens, todas as maletas apresentavam algum sistema de fechamento ou lacre, enquanto que essa função aparecia em $90,9 \%$ dos estojos e apenas entre $8,3 \%$ das bandejas. Quanto às cores, $45 \%$ possuíam apenas uma cor, $30 \%$ eram transparentes/incolores, $17 \%$ tinham duas cores e os demais $8 \%$ tinham 3 ou mais cores, sendo o preto a cor mais utilizada.

Essas análises foram importantes para identificar o atual panorama do mercado para o acondicionamento de mídias de armazenamento, apresentando uma gama de configurações que posteriormente foram filtradas e que auxiliaram no processo de geração de ideias.

O caráter colaborativo nessa etapa se deu pela contribuição dos próprios usuários na busca e sugestão de embalagens similares para análises, que foram levantadas a partir do contato com 
tribunais de outros estados para identificar a forma como esse acondicionamento era realizado nessas instituições. Sua presença também foi constatada nos procedimentos realizados junto aos especialistas, principalmente na complementação, aprofundamento e ratificação das informações. Assim, ambos os grupos atores tiveram conhecimento e participaram da elaboração e da discussão do conjunto de similares, agindo como construtores das análises.

\subsection{Etapa 2: análise, interpretação e organização de dados}

Durante as observações e análises do atual modelo de acondicionamento, foi possível constatar que a embalagem existente para MRs apresenta problemas de usabilidade e estruturais que acabam por interferir no modo de uso e nas suas funções. Não houve a preocupação em relação à análise da resistência do material e do seu dimensionamento, o que acarreta em um excesso de flexibilidade, podendo comprometer a organização e retenção das MRs, além de interferir no empilhamento, manuseio e vida útil das embalagens (Figura 4).

Figura 4 - Problemas detectados na embalagem
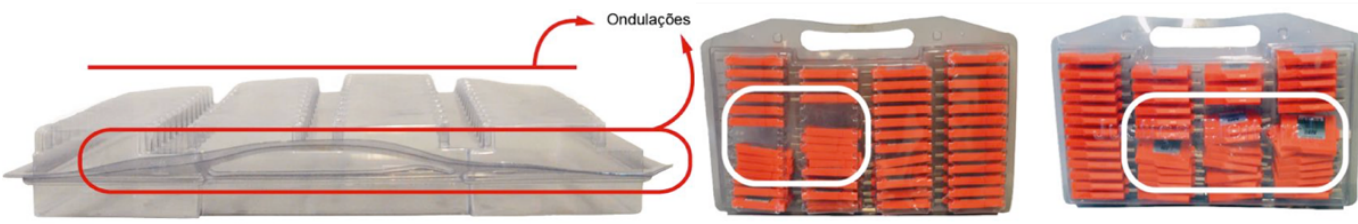

Fonte: autores

Observou-se, também, que a embalagem apresenta fragilidades na sua estrutura resultantes do processo de produção e do material escolhidos (fabricação por termoformagem com uso de Politereftalato de Etileno - PET), o que compromete o seu corpo e contribui para o surgimento de ranhuras, trincas, ondulações e áreas amassadas ou quebradas. Além disso, as fragilidades geram instabilidade quando as embalagens são sobrepostas, o que força a utilização de fitas para garantir que não haja o colapso do conjunto empilhado (Figura 5).

Figura 5 - Fragilidades estruturais da embalagem

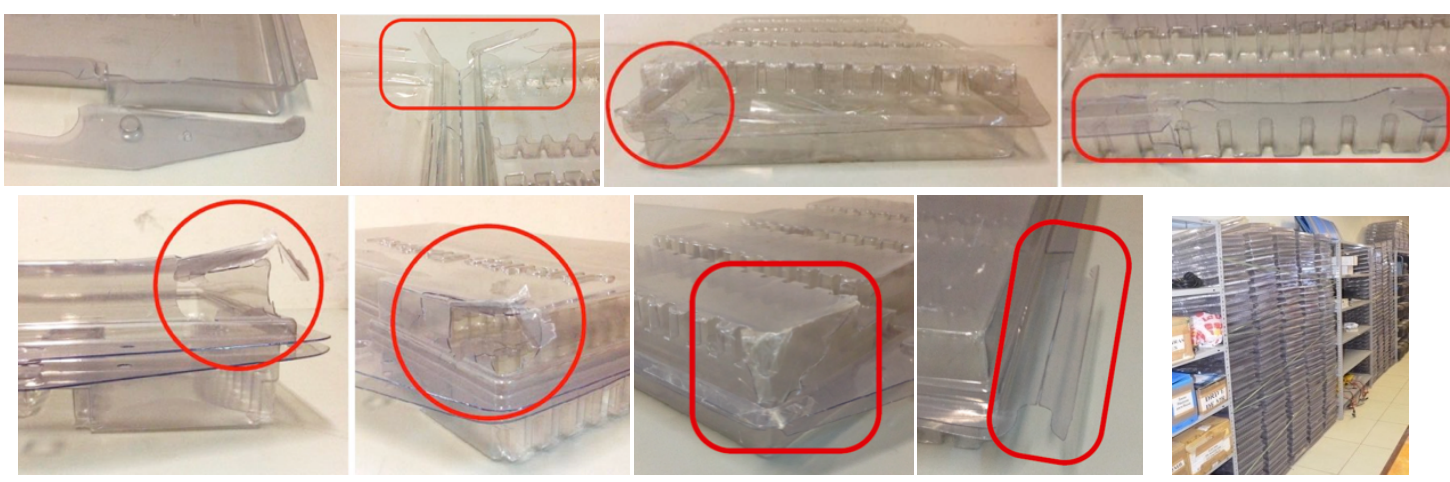

Fonte: autores

Notou-se que o ponto de dobradura não apresentava uma resistência adequada, apresentando-se rompido em algumas áreas, resultando em "cantos vivos" e áreas pontiagudas, o que se mostra como uma fonte de desconforto e de risco para o usuário (Figura 5). O subsistema 
"fechamento" não foi considerado eficaz por não garantir o total fechamento e, ao mesmo tempo, ser de difícil abertura, o que faz com que seja destinada mais força que o ideal para abertura. A área de empunhadura apresentou-se sem conformação com os requisitos de forma e dimensionamento antropométricos, além de apresentar rebarbas e bordas cortantes resultantes do mau acabamento superficial e do processo de produção. Essas configurações vão contra as recomendações apresentadas por lida e Buarque (2016), que afirmam que a presença de protuberâncias e rebarbas na pega são prejudiciais porque concentram pressões nesses pontos.

Diante das informações desta etapa e das etapas anteriores, foi possível gerar o briefing/lista de requisitos baseado em Rodriguez (1986). Reforçando o caráter colaborativo, essa lista de requisitos não foi construída isoladamente pela equipe de design, e contou com a contribuição tanto dos usuários finais quanto dos especialistas, principalmente junto ao especialista em materiais e processos e o especialista em ergonomia, tendo sido aprovada pelos colaboradores antes que fosse iniciada a próxima etapa.

Definiu-se então que, para os requisitos de uso, há a necessidade de melhor contenção das MRs dentro da embalagem, de modo que a leitura do código de barras (patrimônio) seja facilidade e se dê de forma ágil. No que se refere à segurança, a embalagem não deve conter riscos ao usuário, eliminando, portanto, cantos vivos, rebarbas e bordas cortantes, como sugerem lida e Buarque (2016). Ao mesmo tempo, essa contenção não pode permitir movimentações indesejadas das MRs e do conjunto de embalagens.

Para a manipulação e antropometria, são consideradas as diretrizes de Henry Dreyfuss Associates (2005) e lida e Buarque (2016) para controles manuais e manejos, no qual recomendam área para empunhaduras de forma cilíndrica entre 3 a $5 \mathrm{~cm}$ (IIDA; BUARQUE, 2016) ou 32 a $38 \mathrm{~mm}$ (HENRY DREYFUSS ASSOCIATES, 2005), com o intuito de se obter conforto para o usuário.

Para questões de usabilidade, há a necessidade de adequação da embalagem quanto à eficiência, eficácia e satisfação durante o uso, podendo ser citada a necessidade de alterações no processo de inserção e remoção de MRs, além da redução da força demandada e a eficiência no acionamento da abertura e fechamento da embalagem. Sobre a percepção, é preciso proporcionar a compreensibilidade de acondicionamento das MRs, assim como sobre a forma que seu transporte é realizado, apresentando elementos explicativos quanto à sua função principal e sobre a leitura do código de barras (patrimônio) das MRs.

Para os requisitos de função, se faz necessário o desenvolvimento de um sistema de empilhamento. É válida a inclusão de um sistema de abertura e fechamento nas embalagens de forma que não haja possibilidade de abertura acidental ou esforço físico demasiado dos usuários. É necessário permitir o acondicionamento e empilhamento tanto vertical quanto horizontal das embalagens, evidenciando a facilidade de estocagem. Para a resistência, é importante o desenvolvimento de possibilidades que permitam suportar esforços quanto à compressão, tensão ou choque, quedas, agentes externos (umidade, corrosão, intempéries, etc.), atritos e sobreposição de pesos, preservando as MRs. Sobre os requisitos estruturais, deve-se pensar numa quantidade reduzida de componentes, partes e elementos que constituirão a embalagem.

\subsection{Etapa 3: fase de criação}

No processo criativo (Figura 6), ocorreram discussões sobre quais elementos e características seriam capazes de proporcionar inovação, e garantir a praticidade e a 
funcionalidade da proposta da nova embalagem. Por ser um dos pontos de diferenciação da pesquisa, o fator ergonômico ganhou especial atenção, buscando alternativas, referências, normas e recomendações que garantissem a melhor interação dos usuários com o produto.

Figura 6 - Geração de ideais

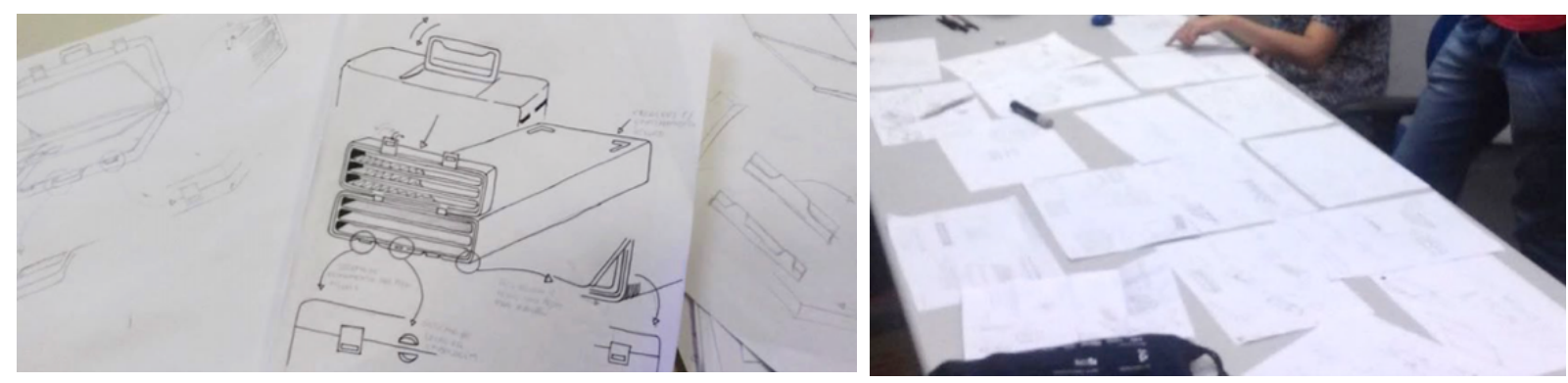

Fonte: autores

Durante as observações, foi possível identificar especialidades do trabalho que contribuíram para o desenvolvimento de propostas que destacavam o quesito praticidade, especialmente nas questões de leitura e armazenamento de MRs. A forma como a estagiária posicionava as MRs (Figura 7), tem como vantagens principais a economia de espaço e a possibilidade de uma maior quantidade de MRs ser posicionada sobre a estação de trabalho para realização da leitura do patrimônio, o que tem impacto no tempo da realização da tarefa.

Figura 7 - Processo de leitura de patrimônio das MRs

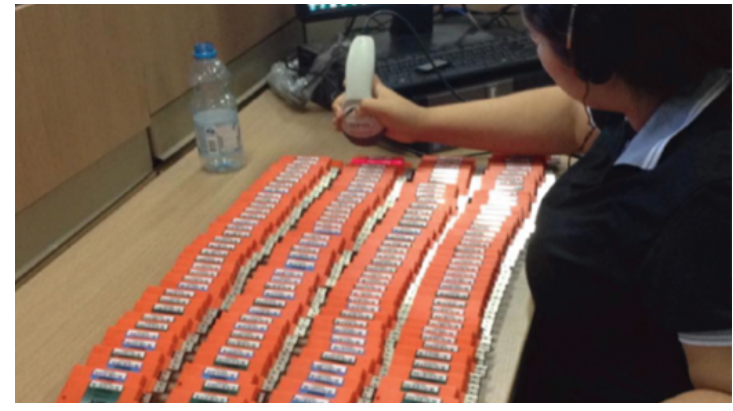

Fonte: autores

A seguir, as propostas geradas que mais se destacaram (Figura 8).

Figura 8 - Principais ideias geradas

(A)

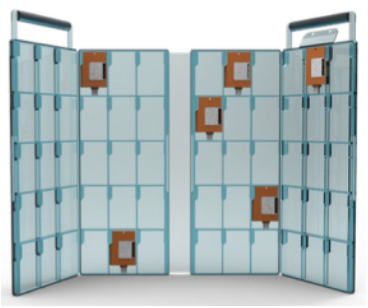

(B)

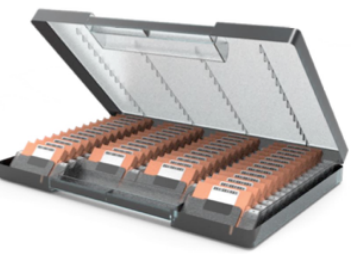

(C)

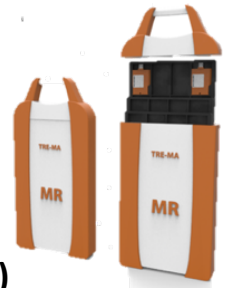

(D)

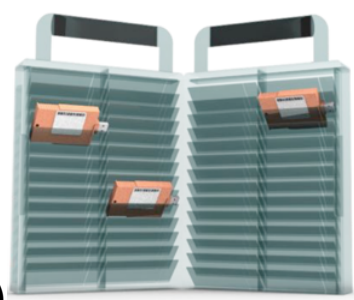

Fonte: autores 
Junto ao desenvolvimento de ideias, foram elaborados quadros comparativos dos possíveis processos de produção e materiais, já sendo feita uma seleção preliminar com base na literatura (LIMA, 2006; NEGRÃO; CAMARGO, 2008). Em seguida, esses quadros foram apresentados aos especialistas e usuários, garantindo a inclusão de suas considerações no procedimento de seleção das alternativas. Durante as apresentações das alternativas por meio da Avaliação Cooperativa e da Técnica Delphi, a proposta que mais se destacou tanto entre os usuários quanto entre os especialistas foi a proposta " $\mathrm{D}$ ", por melhor utilizar o espaço disponível e por apresentar a melhor forma de acondicionamento das MRs, evidenciando o patrimônio para que a leitura seja realizada dentro da própria embalagem, agilizando o processo.

A concordância na escolha tanto dos usuários como dos especialistas sobre a mesma proposta destaca a eficiência no alinhamento de pensamento e na qualidade da comunicação gerada por meio da abordagem colaborativa entre a equipe de design e os demais participantes. Como afirma Kleinsmann (2006, tradução nossa) a colaboração tem impacto direto no sucesso de projeto de produtos. E a comunicação foi uma das bases para que a colaboração fosse efetiva e para que os atores tivessem compreensão do sentido das suas ações e contribuições no projeto, pois como salienta Kleinsmann (2006, p. 250, tradução nossa), "A criação e integração de conhecimento são o objetivo do processo de design colaborativo. Se os atores não forem capazes de criar e integrar conhecimento, eles não serão capazes de projetar um novo produto".

Dentre as alternativas sobre o processo de produção e materiais, o especialista em materiais e processos apresentou como melhor solução a adoção do processo de injeção plástica e o Polipropileno (PP) como o material mais viável, sendo que o PP é classificado como um dos polímeros sintéticos termoplásticos. Segundo Lima (2006), os polímeros desse grupo são caracterizados por serem mais baratos, mais leves, recicláveis e ambientalmente mais limpos, se comparados com os termofixos. Assim, a escolha do material está de acordo com o briefing proposto e com as necessidades destacadas pelos usuários.

\subsection{Etapa 4: executiva}

Tendo sido escolhida a proposta final, foi desenvolvido todo o material representativo para viabilização da produção e também para a apresentação final para os usuários (Figura 9). Mais uma vez, utilizou-se a técnica Delphi para averiguação de todo o detalhamento técnico. Por fim, a proposta foi aprovada com grande aceitação entre os usuários.

Figura 9 - Exemplos do detalhamento técnico realizado
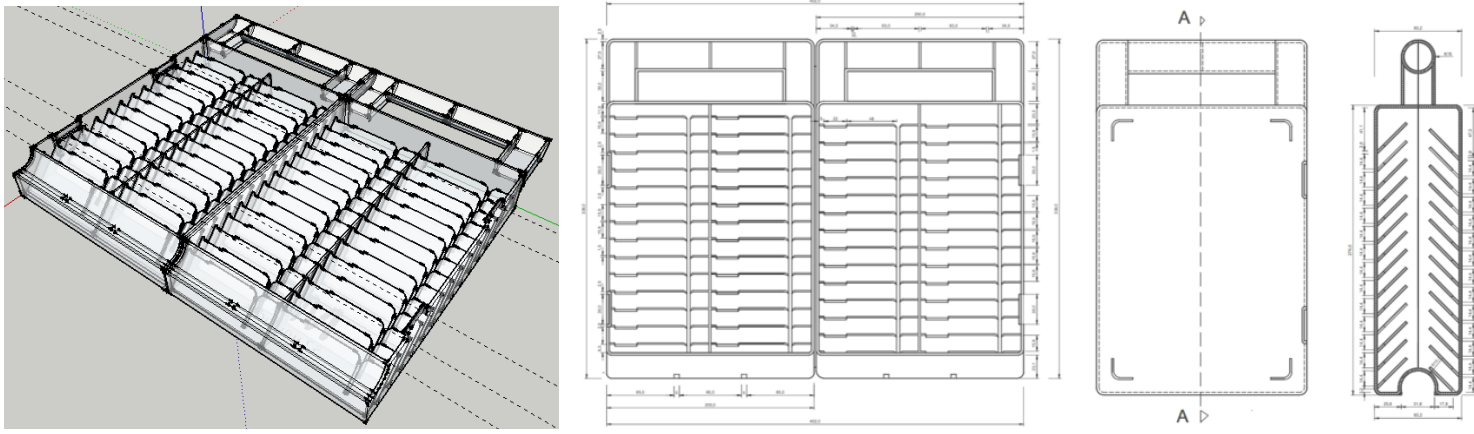

Fonte: autores 


\subsection{Possíveis benefícios da proposta conceitual}

De modo geral, a nova proposta apresenta vários benefícios frente a atual configuração de armazenamento de MRs. Contudo, um elemento em específico merece destaque: a capacidade de armazenamento sofreu mudanças consideráveis em todas as situações observadas. Primeiramente, em cada maleta há um ganho de $4 \%$ na capacidade, passando dos atuais 50 para 52 unidades, o que pode parecer pouco expressivo num primeiro momento, mas esses $4 \%$ representam 1680 MRs de todo o montante do TRE. Isso geraria uma redução de 32 embalagens do total necessário para transportar todas as Memórias de Resultado existentes.

Se antes as maletas não podiam ser guardadas dentro dos armários devido ao seu dimensionamento, com a proposta seria possível acomodar 60 maletas em apenas um armário, número aproximadamente $22 \%$ maior que o número atual de gavetas plásticas que acomodam as MRs. Essa mudança faria ainda com que a capacidade de armazenamento por armário saltasse dos atuais $2.422 \mathrm{com}$ o uso das gavetas para $3.120 \mathrm{MRs}$, um ganho de aproximadamente $29 \%$. Se antes eram precisos 18 armários para armazenar todas as MRs, esse número cai para $14 \mathrm{com}$ a implementação das mudanças. Esses resultados se tornam ainda mais interessantes quando se analisa que é eliminada a necessidade do uso das gavetas plásticas, resultando em economia na aquisição desses componentes. Caso seja observado por um outro ângulo, seria possível afirmar que o TRE já poderia expandir em torno de $30 \%$ seu estoque de MRs que haveriam armários suficientes para acomodá-las com a implementação da proposta.

Resumidamente, os pontos positivos da nova maleta podem ser listados como: maior facilidade na leitura do patrimônio; maior resistência da embalagem às forças externas, resultante de uma série de especificações do projeto como a maior espessura das paredes da embalagem, estruturas internas de suporte, melhor organização das mídias de modo a evitar espaços ociosos, dentre outros; maior durabilidade do material escolhido; o material utilizado garante proteção eletrostática (ESD), pois segundo Bucci (2010), o plástico promove tal proteção, o que é importante para componentes sensíveis, como as memórias flash (o que inclui as MRs); menor ocupação de espaço e eliminação da área destinada para o empilhamento das maletas no setor de suprimentos; novas possibilidades de gerenciamento das MRs, com eliminação de etapas e agilização de procedimentos (facilitação da leitura de patrimônio); ganho em conforto no transporte e manejo da embalagem; eliminação de empilhamento irregular; possibilidade de empilhamento vertical e horizontal das embalagens; eliminação de movimentações indesejadas de MRs dentro da embalagem; sistema de abertura e fechamento mais eficientes; maior segurança para o usuário com a eliminação de fatores de risco como cantos vivos e rebarbas e; mais segurança para o produto acondicionado (MRs).

\section{Considerações Finais}

Ao longo o projeto, desenvolveu-se um detalhamento completo acerca de todos os elementos que compunham o cenário de embalagem e armazenamento de MRs a partir de dados levantados in loco de diferentes ordens (entrevistas, observações, levantamento e análise de embalagens, dentre outros). E utilizou-se uma metodologia projetual específica para o desenvolvimento de embalagens, porém sob uma abordagem colaborativa, que promoveu a integração entre projetistas, especialistas e usuários.

O processo criativo constante resultou em variadas abordagens para o atendimento das necessidades da pesquisa, abordagens essas que sofreram diversas avaliações e aperfeiçoamentos 
pautados nas ferramentas e métodos pré-selecionados, bem como a constante busca pelo olhar técnico de especialistas de áreas variadas.

Vale destacar a importância da abordagem colaborativa ao longo de todo o processo, o que foi essencial para construir as bases que direcionaram aos resultados positivos obtidos. Com a ergonomia e o design colaborativo, várias fontes de informação foram buscadas e geradas em diversos momentos, informações essas que apresentavam uma singularidade de detalhes que dificilmente seria obtida sem um pensar colaborativo. É pertinente destacar ainda que os usuários e especialistas em diversos momentos atuaram como projetistas, não se limitando à checagem de informações ou a seleção de ideias já concebidas. Ambos participaram ativamente no processo de projetação. Portanto, os resultados comprovam a eficiência desta ferramenta e a riqueza que ela fornece por meio dos usuários quando inseridos de forma planejada no processo.

É necessário investigar em estudos posteriores como de fato será a instalação e a eficiência das modificações propostas por meio da análise da inserção em situação real de trabalho da solução gerada. Pretende-se dar continuidade ao desenvolvimento da embalagem pela configuração projetual, até alcançar a fase de testes (validação) para checar a confiabilidade de fabricação e produção. Pretende-se ainda com estudos futuros a expansão das observações para além do Fórum do TRE, alcançando as Zonas Eleitorais, que são os locais que mais demandam o uso das embalagens para o transporte de MRs durante o período eleitoral. A proposta conceitual pode abrir novas possibilidades de gerenciamento e armazenamento de MRs, visto que a inserção da embalagem em situação real possibilitaria economia de espaço, melhor organização e a eliminação de gavetas plásticas dentro dos armários, o que resultaria em uma economia propiciada pela subtração desse recipiente, além garantir um maior conforto e praticidade durante o uso.

\section{Referências}

ABRE - ASSOCIAÇÃO BRASILEIRA DE EMBALAGEM. O papel e funções da embalagem. São Paulo, 2012.

BAXTER, M. Projeto de produto: Guia prático para o desenvolvimento de novos produtos. Editora Edgard Blücher: São Paulo. 1998.

BUCCI, D. Z. Processo de desenvolvimento de produto-embalagem: uma proposta orientada à sustentabilidade. Florianópolis, Tese (Doutorado em Engenharia Mecânica) - Programa de PósGraduação em Eng. Mecânica, Universidade Federal de Santa Catarina (2010), 497p.

COUTINHO, A. et al. 8 Minutes of Collaborative Design. 2010.

FONTANA, I. M. Fatores críticos de sucesso para a colaboração no design de sistemas produtoserviço. Dissertação (Mestrado em Design), Programa de Pós-Graduação em Design, Universidade Federal do Paraná, Curitiba, 2012.

HEEMANN, A.; LIMA, P. J. V.; CORRÊA, J. S. Fundamentos para o Alcance da Colaboração em Design. In: CONGRESSO BRASILEIRO DE PESQUISA E DESENVOLVIMENTO EM DESIGN, 8., 2008, São Paulo. Anais... São Paulo: Aend|brasil, 2010. p. 1338 - 1349.

HENRY DREYFUSS ASSOCIATES. As medidas do homem e da mulher: fatores humanos em design. Porto Alegre: Bookman, 2005. 104 p.

IIDA, I.; BUARQUE, L. Ergonomia: projeto e produção. 3. ed. São Paulo: Blucher, 2016. 
JUSTIÇA ELEITORAL. Manual de Exercitação de Urnas Eletrônicas - modelos: UE2004, UE2006, UE2008, UE2009, UE2010, UE2011. 1a. Edição. Brasília: Tribunal Superior Eleitoral, 2012.

KLEINSMANN, Maaike Susanne. Understanding Collaborative Design.2006. 309 f. Tese (Doutorado) - Curso de Industrial Design Engineering, Delft University Of Technology, Delft, 2006.

LIMA, M. A. M.; Introdução aos materiais e processos para designers. Rio de Janeiro: Editora Ciência Moderna Ltda., 2006.

LÖBACH, B. Design Industrial: bases para a configuração de produtos industriais. 1. ed. São Paulo: Editora Edgard Blücher Ltda., 2001.

MERINO, E. Gestão de design: inovação e integração. Revista ABC Design, edição n. 2, 2002.

MERINO, E; CARVALHO, L. R.; MERINO, G. Design e processo de concepção: Guia de Orientação para o Desenvolvimento de Embalagens. Santa Catarina: UFSC, 2007.

MESTRINER, F. Design de Embalagem - Curso Básico. 2. Ed. São Paulo: Prentice Hall, 2002.

. Embalagem: Design Gráfico. São Paulo, ano 11, n. 94, 2007. p.44 - 47.

MORAES, A. de. MONT'ALVÃO, C. Ergonomia: conceitos e aplicações. Rio de Janeiro: 2AB, 2009.

MORAES, A. de; SANTA ROSA, J. G. Design participativo, técnicas para inclusão de usuários no processo de ergodesign de interfaces. 1. ed. Rio de Janeiro: Rio Book's, 2012.

NEGRÃO, C.; CAMARGO, E. Design de embalagem: do marketing à produção. São Paulo: Novatec Editora, 2008.

PEDELHES, G. J. Embalagem: funções e valores na logística. Florianópolis: GELOG - UFSC, 2005.

PMELINK. Técnicas para estimular a criatividade. 2002.

RICHARD, I. Forças Armadas ajudam a entregar urnas em locais remotos. Brasília: Empresa Brasileira de Comunicação - EBC, 2014.

RODRIGUEZ M.; G. Manual de diseño industrial: Curso Básico. G. Gili. Cidade do México. 1986.

ROMANO, L. N. Metodologia de projeto para embalagem. Florianópolis, Dissertação (Mestrado em Engenharia Mecânica) - Curso de Pós-Graduação em Engenharia Mecânica, Universidade Federal de Santa Catarina, 1996, 172p.

SILVA, J. C. R. P. da; TRABACHINI, T. A. M.; PASCHOARELLI, L. C. A importância dos aspectos ergonômicos no design de embalagens: um estudo bibliométrico. Recife: UFPE, 2015.

TSE - TRIBUNAL SUPERIOR ELEITORAL. Por dentro da urna. 2. Ed., rev. e atual. Brasília: Tribunal Superior Eleitoral, 2010.

Presidente do TSE busca revisão do orçamento para as Eleições 2016. Brasília: Tribunal Superior Eleitoral - Assessoria de Comunicação, 2016.

\section{Agradecimentos}

Ao TRE-MA, por possibilitar o desenvolvimento desta pesquisa; à FAPEMA, pelo auxílio financeiro (bolsa de produtividade); ao Núcleo de Ergonomia em Processo e Produtos (NEPP); à Larissa Ferro e Moisaniel Pimentel pela importante contribuição; à Lívia Campos, Denilson Santos, Francisco Lobo, Karina Bontempo e João Raposo; à Lucilene Cardoso e Bruno Carvalho pela visão. 